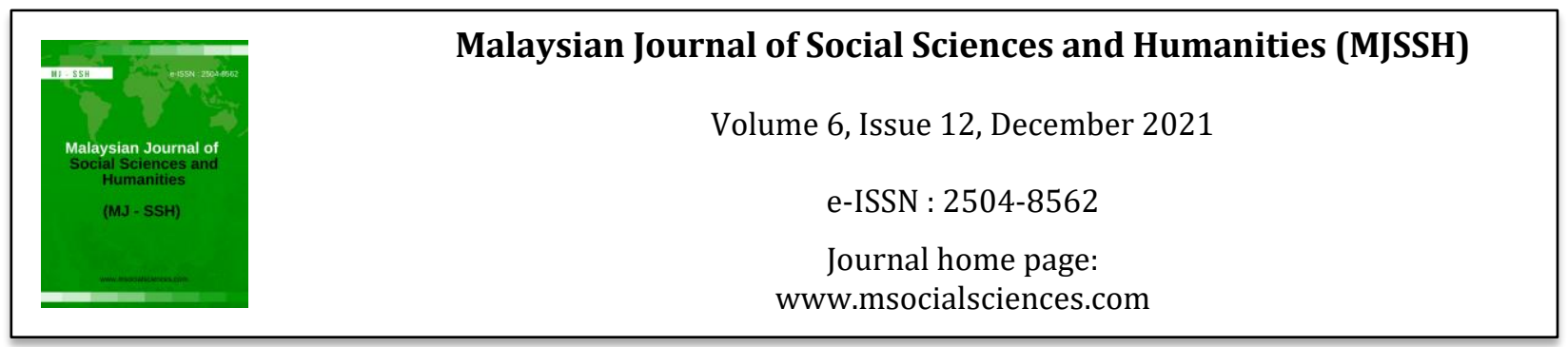

\title{
Pengaplikasian M-Pembelajaran dalam Situasi Pandemik Covid-19: Konsep dan Komponen
}

\author{
Tengku Sarina Aini binti Tengku Kasim¹, Nur Atikah binti Miasan¹ \\ ${ }^{1}$ Academy of Islamic Studies, University of Malaya (UM), Malaysia \\ Correspondence: Tengku Sarina Aini Tengku Kasim (tgsarina@um.edu.my)
}

\begin{abstract}
Abstrak
Pandemik Covid-19 yang melanda seluruh dunia menuntut perubahan drastik dalam kebanyakan urusan kehidupan harian bagi menyekat dan menghapuskan rantaian wabak tersebut. Hampir seluruh dunia melakukan sekatan pergerakan (lockdown) dan Perintah Kawalan Pergerakan (PKP) turut dilaksanakan, termasuk di Malaysia. Pembelajaran secara maya telah diperkenalkan dalam memperkayakan pendekatan pendidikan yang bersesuaian dengan keperluan semasa. Dalam situasi ini, m-pembelajaran menjadi satu trend yang diguna pakai bagi menjalankan sesi pembelajaran dan pemudah caraan secara maya di seluruh peringkat institusi pendidikan. Pengaplikasian m-pembelajaran dalam pelbagai disiplin ilmu semakin meningkat lantaran konsep dan komponennya yang bersesuaian dengan fenomena semasa. Artikel ini akan membincangkan kepentingan pengaplikasian mpembelajaran dalam situasi pandemik, di mana konsep dan komponen penting dalam m-pembelajaran akan difokuskan.
\end{abstract}

Kata kunci: pandemik, m-pembelajaran, PdPR, persekitaran m-pembelajaran

\section{The Application of M-Learning in Covid-19 Pandemic Situations: Concepts and Components}

\begin{abstract}
The Covid-19 pandemic which had hit the whole world demanded drastic changes in most affairs of daily life to curb and eliminate the chain of the epidemic. Lockdowns and Movement Control Orders (MCO) are also implemented in many countries across the world, including Malaysia. Virtual learning has been introduced in enriching educational approaches to suit current needs. In this situation, mlearning has become a trend that is adopted to conduct virtual learning and facilitation sessions at all levels of educational institutions. The application of $\mathrm{m}$-learning in various disciplines is increasing due to its concepts and components that are appropriate to current phenomena. This article will discuss the importance of the application of m-learning in pandemic situations, where important concepts and components in m-learning will be focused.
\end{abstract}

Keywords: pandemic, m-learning, PdPR, m-learning environment 


\section{Pengenalan}

Salah satu daripada kesan pandemik COVID-19 dapat dilihat dengan penutupan Institusi Pengajian Tinggi (IPT) dan sekolah dalam tempoh Perintah Kawalan Pergerakan (PKP). Institusi Pengajian Tinggi (IPT) dan peringkat persekolahan telah mengubah kaedah pelaksanaan pembelajaran. Struktur pembelajaran dan pengajaran (PdP) secara langsung dan bersemuka telah bertukar kepada PdP dalam talian secara sepenuhnya. Dalam situasi pandemik Covid-19 melanda negara, e-pembelajaran menjadi medium yang paling berkesan bagi menggantikan sistem pendidikan secara tradisional. Kerajaan Malaysia juga telah membenarkan pelbagai aplikasi alam maya atau platform digital yang bersesuaian untuk digunakan seperti Whatsapp, Google Classroom, Zoom, Webex, YouTube dan sebagainya untuk meneruskan aktiviti PdP dalam tempoh Perintah Kawalan Pergerakan (PKP). PdP secara alam maya ini memerlukan kerjasama dan komitmen yang padu daripada semua pihak, sama ada melibatkan aspek pengetahuan, kefahaman mahupun kemahiran, berkaitan dengan pengaplikasian teknologi maklumat, penyediaan peranti digital, akses capaian internet serta kaedah pembelajaran dan penilaian.

E-pembelajaran diperkenalkan agar pendidik dapat menarik minat pelajar dan mentransformasikan pengajaran secara tradisional kepada pengajaran berteraskan teknologi. Melalui e-pembelajaran, pendidik dapat menyampaikan pengetahuan kepada pelajar sama ada melalui video, audio, gambar, dan juga komunikasi teks. E-pembelajaran telah menjadi kaedah yang paling berkesan dan digemari oleh golongan pelajar dan pensyarah untuk diaplikasikan bagi menyampaikan ilmu dan mencari pelbagai maklumat berkaitan pendidikan seperti mencari nota-nota rujukan tambahan, soalan-soalan tahun lepas, berkongsi pandangan dan bertanya pendapat tentang sesuatu tugasan ataupun latihan menerusi ruangan sosial di internet. Pengaplikasian teknologi maklumat dan komunikasi (Information and Communications Technology) memberikan peluang kepada pelajar untuk menerima pembelajaran dan mengaplikasikan kemahiran-kemahiran yang diperlukan di alaf 21 .

Malah, dalam menempuh pembelajaran abad ke-21 (PAK21), guru juga dikehendaki mengaplikasikan pedagogi yang menggunakan strategi, pendekatan, kaedah dan teknik pembelajaran yang baharu, bersesuaian dengan era globalisasi dan teknologi maklumat. Guru dikehendaki mengaplikasikan pendidikan yang menjurus ke arah pelbagai bentuk kemahiran abad ke-21, antaranya seperti Kemahiran Berfikir Aras Tinggi (KBAT), yang mana telah pun diintegrasikan dalam pendidikan di luar negara seperti Amerika Syarikat dan England, iaitu sejak tahun 1970an lagi. PAK-21 yang menekankan elemen komunikasi, kolaboratif, kritis dan kreatif memerlukan guru untuk mempelbagaikan pendekatan PdPc. Sehubungan dengan itu, pendekatan melalui m-pembelajaran membuka ruang interaksi yang lebih luas antara guru dengan pelajar, pelajar sesama pelajar dan juga pelajar dengan bahan pembelajaran (Tengku Sarina Aini, Nur Atikah \& Yusmini, 2020).

M-pembelajaran (Mobile Learning) boleh ditakrifkan sebagai pembelajaran menggunakan peranti atau teknologi yang bersifat mudah alih seperti penggunaan komputer riba dan telefon bimbit sebagai medium pembelajaran. Selain itu, m-pembelajaran juga dilihat sebagai revolusi daripada pembelajaran elektronik (e-Learning) dan pembelajaran teradun (blended learning). Pengaplikasian pelbagai peranti mudah alih dalam pembelajaran merupakan seni dalam penggunaan teknologi dalam pendidikan untuk meningkatkan pengalaman pembelajaran.

Dalam era pandemik, pengaplikasian m-pembelajaran memberi kebebasan kepada guru dan pelajar untuk memilih medium pembelajaran yang efektif mengikut situasi mereka. Penggunaan pelbagai variasi peranti mudah alih yang semakin meluas memberi kemudahan kepada guru dan juga pelajar untuk melaksanakan m-pembelajaran dengan efektif walaupun mereka berada dalam tempoh Perintah Kawalan Pergerakan (PKP).

\section{Konsep M-Pembelajaran}

Konsep m-pembelajaran didefinisikan sebagai pembelajaran yang tidak terikat dengan ruang masa dan tempat serta bersifat mudah alih dari segi fungsi dan teknologinya (Saedah \& Muhammad Helmi, 
2012; Md Yusoff, Fariza, \& Norhayati, 2016). Konsep ini menekankan aspek mobiliti iaitu keupayaan pengguna untuk memudah alihkan proses pembelajaran tanpa terikat dengan fizikal kelas.

Aspek mobiliti dapat dikelaskan kepada tiga bahagian dalam pelaksanaan m-pembelajaran, iaitu mobiliti teknologi, yang merujuk kepada kemajuan teknologi tanpa wayar; mobiliti pembelajaran, yang merujuk kepada penyampaian isi pembelajaran bersifat mudah alih; dan mobiliti pelajar iaitu keberadaan pelajar yang tidak terikat dengan masa dan tempat (Nor Fadzleen, Halina, \& Ibrahim, 2013). Oleh itu, antara ketiga-tiga aspek ini perlu bersifat mudah alih untuk pelaksanaan mpembelajaran.

Komponen utama peranti m-pembelajaran ialah kemajuan peranti dan jaringan internet. Peranti yang memiliki kemajuan teknologi terkini akan memudahkan sesi pembelajaran berlangsung, seiring dengan keperluan semasa. Manakala jaringan internet pula merujuk kepada peranti yang boleh disambungkan kepada internet tanpa menggunakan wayar. Selain itu, peranti m-pembelajaran juga perlu mempunyai ciri fizikal saiz yang padat serta tidak memerlukan masa yang lama untuk konfigurasi sama ada ditutup ataupun dibuka (Caudill, 2007).

Secara umumnya, teknologi peranti mudah alih mempunyai ciri-ciri mobiliti yang menyokong pelaksanaan m-pembelajaran. Dengan kemajuan teknologi terkini, kebanyakan peranti mudah alih mempunyai semua komponen utama ini.

Berdasarkan kajian lepas, komputer riba dan telefon pintar mudah alih merupakan alat mpembelajaran yang dominan (Aliff \& Mohd Isa, 2013; Ghavifekr et al., 2014; Fairose et al., 2017). Situasi keperluan semasa pada zaman kini menjadikan dua peranti tersebut sebagai keutamaan bagi pelajar dan juga tenaga pengajar. Tambahan pula aplikasi jaringan mudah alih untuk telefon bimbit lebih ekonomi dari segi kosnya dan mudah untuk digunakan (Afendi et al., 2013).

Peranti yang terdapat dalam pasaran terkini dilengkapi dengan pelbagai aplikasi asas seperti kemudahan kamera, pemutar lagu dan video, galeri gambar, sambungan wifi secara terus ataupun paparan tanpa wayar dan sistem kedudukan sejagat (GPS), bergantung kepada model dan jenama sesuatu peranti. Setiap aplikasi yang dibekalkan dari kilang dan yang dimuat turun secara percuma ataupun berbayar boleh dimanfaatkan dalam m-pembelajaran.

Potensi m-pembelajaran semakin meluas dengan wujudnya akses internet. Terdapat pelbagai perisian dan aplikasi boleh dimuat turun secara berbayar ataupun percuma yang menjadi sokongan kepada pelaksanaannya bergantung kepada peranti mudah alih yang digunakan. Pengguna boleh menentukan perisian dan aplikasi berdasarkan keperluan dan tanggungjawab masing-masing. Setiap aplikasi yang dimuat turun dan dipasang dalam peranti mudah alih merupakan kemudahan asas yang dipilih oleh pengguna sebagai sumber yang menyokong pembelajaran dan pemudah caraan mereka (Pimmer et al., 2019). Hal ini kerana setiap peranti mudah alih mempunyai fungsi yang berlainan yang membolehkan perkongsian pembelajaran berlaku tanpa mengambil kira bentuk media isi pembelajaran dan cara penyampaiannya (Cochrane, 2010; Mohamed Amin \& Norazah, 2013).

Perisian perlu sesuai dengan tuntutan kerja guru untuk membantu pelaksanaan pembelajaran dan pemudah caraan di dalam kelas (Heflin et al., 2017). Antara aplikasi yang boleh digunakan adalah seperti OneNote daripada Microsoft, QR Code Reader, PDF Reader, al-Quran dan pelbagai nota-nota rujukan yang disediakan oleh syarikat-syarikat penerbit buku seperti Sasbadi, Oxford Fajar dan Telaga Biru.

Selain itu, kewujudan word processor bagi telefon mudah alih turut menjadi satu keperluan dalam setiap peranti bagi mewujudkan persekitaran pembelajaran secara individu. Antara aplikasi yang popular ialah Word, Kingsoft Office, Polaris Office dan Office Suit. Pelbagai aplikasi yang wujud menambah baik fungsi peranti mudah alih. Justeru, pengguna hanya perlu memilih untuk mendapatkannya sama ada secara percuma ataupun berbayar. 
Begitu juga dengan kemudahan yang lain seperti e-mel, diari, pemain audio dan video, photo sharing, web browser, instant messaging dan pelbagai aplikasi sosial seperti WeChat, WhatsApp, Facebook dan Instagram memudahkan perkongsian maklumat antara pelajar dan dunia maya, menjadikan peranti mudah alih sebagai alat interaktif pelbagai fungsi (Pimmer et al., 2019).

Melalui fungsi yang pelbagai, penyampaian maklumat dan isi pelajaran menggunakan peranti mudah alih yang berorientasikan pembelajaran elektronik dibina dalam pelbagai bentuk. Antaranya adalah seperti berikut:

i. Media cetak (elektronik) seperti petikan, jurnal, buku, dan majalah elektronik

ii. Video seperti video editor, klip dan rakaman video

iii. Audio

Sumber-sumber media tersebut dapat dicapai melalui pembelajaran berasaskan laman sesawang (web) yang pelbagai, sesuai dengan keperluan pengguna dan maklumat yang diperlukan. Kewujudan sumber dan media elektronik sekali gus membentuk persekitaran bilik darjah maya (virtual classroom).

\section{Persekitaran M-Pembelajaran}

Perkembangan capaian internet yang meluas dan inovasi teknologi moden telah meningkatkan penggunaan peranti mudah alih sebagai salah satu medium pembelajaran. Melalui pendekatan mpembelajaran, persekitaran pembelajaran menjadi lebih fleksibel dan boleh disesuaikan mengikut aktiviti dan sumber pembelajaran yang pelbagai. Sumber pendidikan tidak terhad kepada buku, jurnal dan pengetahuan guru semata-mata (Wan Mohd Fauzy, 2012). Inovasi ini telah mengubah peranan guru daripada tenaga pengajar kepada pemudahcara pembelajaran untuk membantu pelajar mencapai objektif.

Dalam konsep m-pembelajaran, kualiti pembelajaran adalah bergantung kepada dua pihak, iaitu guru dan pelajar. Guru perlu menyediakan bahan dan merancang aktiviti pembelajaran dan pemudah caraan dengan teliti agar dapat menghasilkan pembelajaran berkesan dengan mempertimbangkan perbezaan antara pelajar (Lai et al., 2016). Manakala pelajar pula perlu berusaha untuk mencapai bahan pembelajaran di luar daripada kebiasaannya yang bersumberkan daripada buku dan guru sahaja. Selain itu, komunikasi dan interaksi sesama pelajar dan antara guru dengan pelajar akan menjadi lebih efektif dengan penggunaan m-pembelajaran (Naseer, 2016). Komunikasi dan interaksi ini dilaksanakan melalui pelbagai laman sosial yang wujud pada masa kini seperti medium WhatsApp, Instagram dan Telegram.

Interaksi secara maya yang berlaku antara guru dan pelajar melalui laman sosial dapat menimbulkan keseronokan belajar (Moorthy et al., 2019). Kesannya, motivasi pelajar akan meningkat untuk terus menggunakannya sebagai medium pembelajaran walaupun komunikasi berlaku di luar waktu persekolahan (Hsieh \& Tsai, 2017; Ooi, Hew \& Lee, 2018). Secara tidak langsung, pelajar terdorong untuk mendapatkan bahan pembelajaran serta menerima perkongsian bahan secara langsung daripada guru tanpa terikat dengan batas masa dan fizikal kelas.

Seiring dengan tuntutan transformasi pendidikan dalam negara, inisiatif kementerian untuk meningkatkan taraf pendidikan dalam negara ke arah pembelajaran abad ke-21, konsep pembelajaran maya turut diperkenalkan sebagai salah satu usaha ke arah pembelajaran masa hadapan (Kementerian Pendidikan Malaysia, 2013). Daripada Frog Virtual Learning Environment (Frog VLE) yang diperkenalkan pada tahun 2012-2019, laman pembelajaran maya dinaik taraf kepada Digital Educational Learning Initiative Malaysia (DELIMa) yang dikuasakan oleh syarikat gergasi Google. Portal pendidikan maya ini disediakan oleh Kementerian Pendidikan Malaysia kepada semua guru dan pelajar (http://portal.moe-dl.edu.my/ ).Terdapat lebih daripada 10 aplikasi Google dan Microsoft yang boleh digunakan secara percuma oleh guru dan pelajar untuk tujuan pembelajaran maya. Antara aplikasi yang sinonim dengan pembelajaran maya adalah Google Classroom, Google Meet dan Microsoft Teams. Laman ini boleh dicapai menggunakan pelbagai jenis peranti yang dilengkapi dengan jaringan internet. 
Walaupun terdapat pelbagai kemudahan pembelajaran maya kepada guru dan pelajar pada masa kini, guru sebagai pemudah cara perlu meneliti penyusunan sesi pembelajaran. Guru perlu merancang setiap sesi pembelajaran agar dapat berjalan dengan baik, terkawal dan memberikan kesan kepada pelajar. Dalam konsep m-pembelajaran di situasi pandemik kini, guru perlu menyusun aktiviti yang bersesuaian dengan tahap pelajar bagi meraikan perbezaan literasi teknologi, ketersediaan peranti serta kesesuaian pelaksanaannya untuk pelajar (Hung et al., 2015).

\section{Komponen Penting dalam M-Pembelajaran}

Berdasarkan ciri peralatan dan persekitaran m-pembelajaran, terdapat beberapa komponen yang perlu dipertimbangkan dalam menjayakan pelaksanaannya. Antaranya adalah seperti berikut:

\section{Pelantar pembelajaran maya atau 'Learning Management System' (LMS)}

Di Malaysia, kemudahan ini telah disediakan melalui portal DELIMa. Portal tersebut turut menyediakan aplikasi pembelajaran dan pemudah caraan yang pelbagai untuk pelajar dan guru. Selain itu, pentadbir untuk domain disediakan dalam setiap sekolah bagi memudahkan pengurusan pembelajaran dilaksanakan.

\section{Aplikasi yang digunakan untuk menyampaikan isi pembelajaran}

Aplikasi ini bersifat umum, sama ada berbentuk dalam talian termasuklah laman sesawang yang menawarkan aktiviti pembelajaran berkonsepkan edutainment seperti Kahoot, Quizziz, Blendspace, Gather Town dan sebagainya. Selain itu, aplikasi sokongan yang digunakan oleh guru dan pelajar untuk memaparkan tulisan atau idea seperti google whiteboard, google doc, one note dan microsoft whiteboard. Manakala aplikasi luar talian pula adalah perisian yang dimuat turun dan dipasang ke dalam peranti seperti Microsoft Office. Semua aplikasi ini boleh digunakan untuk tujuan pembelajaran ataupun pelaksanaan aktiviti dan penilaian. Melalui aplikasi yang dipilih akan mendorong kepada interaksi guru dan pelajar, pelajar sesama pelajar dan juga pelajar dan bahan pembelajaran.

\section{Bentuk komunikasi antara guru dan pelajar}

Komunikasi yang berlaku adalah sangat penting bagi menyampaikan isi pembelajaran. Bentuk pelaksanaannya akan mempengaruhi tahap kefahaman pelajar untuk menerima perkongsian ataupun arahan daripada guru. Komunikasi boleh dilaksanakan sama ada berbentuk teks mesej, audio suara, rakaman video atau panggilan video. Pemilihan bentuk komunikasi turut melibatkan pemilihan aplikasi yang bersesuaian untuk melakukan interaksi antara guru dan pelajar. Contohnya melalui panggilan video persidangan, interaksi yang berlaku adalah secara bersemuka dalam talian menggunakan aplikasi seperti Google Meet, Microsoft Teams, Webex atau Zoom.

\section{Pemilihan pendekatan, strategi dan kaedah pemudah caraan guru}

Pembelajaran bermakna merupakan tujuan utama dalam menjalankan sesi pembelajaran dan pemudah caraan (PdPc). Walaupun pembelajaran boleh berlaku tanpa terikat dengan fizikal kelas, guru tetap perlu merancang pemilihan strategi dan kaedah pemudah caraan agar sesi yang berlangsung dapat memberi makna kepada pelajar. M-pembelajaran memudahkan guru dan pelajar dari segi ruang dan masa, namun penyampaian isi pembelajaran, pelaksanaan aktiviti dan pentaksiran perlu dirancang dengan teliti agar dapat mengoptimumkan sesi PdPc yang berlangsung.

\section{Kajian Pengaplikasian M-Pembelajaran Semasa Pandemik}

Sebelum pandemik berlaku, m-pembelajaran tidak digunakan sepenuhnya sehinggalah kekangan yang mengehadkan kelas bersemuka dilaksanakan seperti sedia kala. Apabila semua institusi diarahkan tutup, sesi PdPc secara bersemuka berubah secara drastik kepada pembelajaran dalam talian dan 
konsep PdPr (pengajaran dan pembelajaran dari rumah) diperkenalkan. Semua guru dan pelajar sekolah menggunakan pelbagai medium dalam talian untuk meneruskan sesi pembelajaran mereka dan konsep m-pembelajaran telah digunakan secara tidak langsung. Dalam situasi luar jangkaan ini, terdapat kelebihan dan cabaran yang dihadapi oleh warga pendidik serta para pelajar untuk melaksanakan m-pembelajaran.

Kajian oleh Mohd Fadli dan Sharifuddin (2019) mendapati para pelajar tidak mempunyai masalah untuk meneruskan proses pembelajaran dalam talian menggunakan m-pembelajaran. Mereka menjelaskan bahawa kesediaan pelajar dalam proses pembelajaran adalah pada kadar yang agak tinggi. Ini disokong oleh dapatan kajian oleh Wahyudin, Yuli, Ali dan Muhlas (2020) yang mendapati bahawa pembelajaran dalam talian adalah terbukti berkesan dilaksanakan semasa BDR (Bekerja dari Rumah) yang diakibatkan oleh pandemik COVID-19. Kajian mereka mengesyorkan bahawa betapa pentingnya mengembangkan idea dalam melaksanakan pembelajaran secara dalam talian.

Walau bagaimanapun, beberapa kajian yang dijalankan oleh penyelidik turut mendapati cabaran dalam pembelajaran dalam talian mengaplikasikan m-pembelajaran. Antaranya, kajian yang dijalankan oleh Briliannur et al. (2020), yang mendapati bahawa pembelajaran secara dalam talian bagi pelajar sekolah adalah kurang berkesan kerana wujudnya kekangan ekonomi dari segi sarana dan prasarana. Kajian mereka turut mendapati para pelajar tidak bersedia dari segi teknologi, sama ada dari segi akses pencapaian internet mahupun kekurangan sumber maklumat mengenai penyediaan teknologi mudah alih pada masa kini.

Begitu juga kajian yang dijalankan oleh Munirah, Faisal, Syaheeda dan Julia (2021) yang mendapati bahawa pembelajaran dalam talian adalah kurang efektif dan tidak bermotivasi berbanding dengan pembelajaran secara bersemuka dalam kalangan pelajar. Munirah et al. (2021) juga menyatakan kesediaan pelajar terhadap pembelajaran dalam talian adalah baik, namun perlulah seiring dengan capaian internet yang baik dan peranti elektronik yang bersesuaian. Hasil penyelidikan Kok (2021) juga mendapati bahawa kesediaan pelajar dalam pembelajaran dalam talian adalah sederhana berbanding pembelajaran secara terbuka.

Kajian oleh Tengku Sarina Aini, Nur Atikah dan Yusmini Md Yusoff (2020) juga turut mendapati terdapat beberapa cabaran dalam kalangan guru novis untuk mengaplikasikan m-pembelajaran secara efektif. Cabaran pengaplikasian m-pembelajaran yang dihadapi oleh informan dalam kajian tersebut telah dikategorikan kepada dua bahagian, iaitu cabaran dari segi pengetahuan dan kemahiran, serta perbezaan latar belakang pelajar. Cabaran paling ketara adalah berkaitan kekurangan pengetahuan dalam strategi PdPc menggunakan m-pembelajaran. Kajian mendapati tidak semua informan menerima bimbingan yang sepatutnya berkaitan pengamalan m-pembelajaran. Dapatan kajian mendapati bimbingan berkenaan pengaplikasian m-pembelajaran hanya diberikan secara maya ketika pandemik mula merebak di Malaysia.

Berikut merupakan respons daripada beberapa orang guru dalam kajian berkenaan:

"Saya dan rakan guru sekolah diberikan taklimat dan berbengkel secara maya menggunakan Google Meet oleh guru ICT masa bulan Mac (tahun 2020) hari tu. Tetapi pelaksanaannya masih terhad bagi saya sebab saya masih perlukan masa untuk memahami dengan baik kandungan serta visi kurikulum baru [baharu]”.

"Saya join [sertai] bengkel pembelajaran maya secara sukarela anjuran Pusat Kegiatan Guru Daerah kerana minat. Di sekolah pun ada diberikan taklimat dan bengkel, cuma untuk mendalami dengan lebih lagi bagi memudahkan saya mengajar pelajar sepanjang cuti Covid-19 ni”.

"Kalau rujuk dengan orang pun, tiada [sesiapa] yang boleh ajar dengan baik. Contohnya kan, kalau kita guna pun m-learning ni untuk fasa pandemik untuk PdPc jarak jauh bila pelajar tidak hadir [ke sekolah], tapi tiada guide [bimbingan] macam mana [bagaimana] kita mahu masukkan elemen $4 K$ dalam 


\section{PAK-21. Jadi, atas usaha dan fikiran sendiri tu lah saya cuba menyusun dan} menggabungkan pengetahuan yang ada".

Sesetengah guru memerlukan bimbingan teknologi secara hands-on bagi meningkatkan keyakinan mereka untuk menggunakan m-pembelajaran, terutamanya golongan pendidik yang berumur (Saikat et al., 2021). Namun, mereka menerima dengan positif untuk menggunakan pendekatan m-pembelajaran walaupun bimbingan dilaksanakan secara dalam talian (Mohd Razali, Zanaton, Fariza, 2021). Tempoh adaptasi diperlukan agar mereka dapat mengukuhkan cara mengaplikasikannya bersama pelajar (Matzavela \& Alepis, 2021). Oleh itu, kekurangan bimbingan dalam menggunakan m-pembelajaran dapat diatasi apabila situasi menekan seperti sekarang ini menuntut guru untuk melakukan transformasi drastik dalam menjalankan sesi PdPR.

Setiap sesi pembelajaran memerlukan guru untuk melakukan pentaksiran. Tetapi cabaran melaksanakan pentaksiran dalam talian adalah isu ketelusan respon pelajar ketika menjawab (Saikat et.al, 2021). M-pembelajaran memudahkan guru dan pelajar, sehingga sangat mudah untuk pelajar mendapatkan bantuan luar untuk menjawab soalan-soalan penilaian. Oleh itu, penggunaan $\mathrm{m}-$ pembelajaran sebagai medium penilaian perlu diteliti bagi mengatasi isu plagiat jawapan antara pelajar.

Walaupun terdapat cabaran yang dihadapi dalam pelaksanaannya, kajian lepas turut memfokuskan kelebihan yang sangat sinonim dengan keperluan guru serta pelajar. Antara yang paling dominan ialah ketersediaan resos dan bahan pembelajaran maya (Mohd Razali, Zanaton, Fariza, 2021; Saikat et.al, 2021). Dengan wujudnya sumber bahan pembelajaran maya, pelajar boleh mencapai maklumat tanpa batas melalui kaedah m-pembelajaran yang dilaksanakan. Secara tidak langsung, pelajar dapat melaksanakan pembelajaran kendiri.

\section{Kesimpulan}

Pendidikan merupakan salah satu aspek yang penting dalam negara. Walaupun mengalami pandemik, sesi pembelajaran tidak boleh diabaikan begitu sahaja. Tambahan pula, dengan penetapan peraturan penjarakan fizikal, sesi persekolahan perlu 'dipindahkan' ke alam maya. Kekangan yang berlaku ini telah membuka ruang seluasnya untuk adaptasi m-pembelajaran. Artikel ini menjelaskan konsep asas berkaitan m-pembelajaran agar dapat diaplikasikan semasa situasi pandemik ini. Walaupun terdapat cabaran dalam pelaksanaannya, namun kelebihan dan keperluan untuk menggunakannya mengatasi cabaran yang perlu dihadapi. Secara tidak langsung menunjukkan penerimaan yang sangat positif dalam kalangan pendidik dan pelajar untuk menggunakan m-pembelajaran. Justeru, sebelum menyatakan 'm-pembelajaran adalah satu kaedah yang sangat berguna untuk pembelajaran', adalah digalakkan untuk mengkaji semula penentu yang boleh mempengaruhi penggunaan sebenar $\mathrm{m}$ pembelajaran. Fokus kajian akan datang adalah dengan melihat sejauh mana faktor kualiti bahan pembelajaran dapat mempengaruhi keputusan pelajar untuk menerima m-pembelajaran dalam krisis masa depan. Hasil kajian tersebut diharapkan dapat membantu untuk membentuk trend pembelajaran digital pada masa hadapan menggunakan peranti-peranti pintar mudah alih.

\section{Rujukan}

Afendi Hamat, Mohamed Amin Embi, \& Haslinda Abu Hassan. (2013). Preparing for mobile learning: A readiness study at Universiti Kebangsaan Malaysia. In Mohamed Amin Embi \& Norazah Mohd Nordin (Eds.), Mobile Learning: Malaysian Initiatives \& Research Findingss (pp. 19-25). Kementerian Pengajian Tinggi.

Aliff Nawi, \& Mohd Isa Hamzah. (2013). Tahap penerimaan penggunaan telefon bimbit sebagai mpembelajaran dalam Pendidikan Islam. Journal of Islamic and Arabic Education, 5(1), 1-10.

Briliannur Dwi C, Aisyah Amelia, Uswatun Hasanah, Abdy Mahesha Putra \& Hidayatur Rahman. (2020). Analisis Keefektifan Pembelajaran Online di Masa Pandemik Covid-19. MAHAGURU: Jurnal Pendidikan Guru Sekolah Dasar, 28-37. 
Caudill, J. (2007). The growth of m-learning and the growth of mobile computing: Parallel developments. International Review of Research in Open and Distance Learning, 8(2), 1-14.

Cochrane, T. D. (2010). Exploring mobile learning success factors. Research in Learning Technology, 18(2), 133-148. https://doi.org/10.1080/09687769.2010.494718

Fairose Shamsudin, Jamaludin Badusah, \& Muhamed Amin. (2017). Penggunaan m-pembelajaran: Satu inovasi dalam pembelajaran Bahasa Melayu. Seminar on Transdisciplinary Education (STEd 2017), 719-726.

Ghavifekr, S., Ahmad Zabidi Abd Razak, Muhammad Faizal A. Ghani, Ran, N. Y., Yao Meixi, \& Tengyue, Z. (2014). ICT integration in education: Incorporation for teaching and learning improvement. Malaysian Online Journal of Educational Technology, 2(2), 24-54.

Heflin, H., Shewmaker, J., \& Nguyen, J. (2017). Impact of mobile technology on student attitudes, engagement and learning. Computers \& Education, 107, 91-99. https://doi.org/10.1016/j.compedu.2017.01.006

Hsieh, W. M., \& Tsai, C. C. (2017). Taiwanese high school teachers' conceptions of mobile learning. Computers and Education, 115, 82-95. https://doi.org/10.1016/j.compedu.2017.07.013

Hung, H. C., Young, S. S. C., \& Lin, C. P. (2015). No student left behind: a collaborative and competitive game-based learning environment to reduce the achievement gap of EFL students in Taiwan. Technology, Pedagogy and Education, 24(1), 35-49. https://doi.org/10.1080/1475939X.2013.822412

Kementerian Pendidikan Malaysia. (2013). Malaysia education blueprint 2013-2025. In Kementerian Pendidikan Malaysia. https://doi.org/10.1016/j.tate.2010.08.007

Kok, K. H. (2020). Interaksi tidak bersemuka dan perintah kawalan pergerakan wabak covid-19. Jurnal Dunia pendidikan, 2(3), 202-211.

Lai, C.-L., Hwang, G.-J., Liang, J.-C., \& Tsai, C.-C. (2016). Differences between mobile learning environmental preferences of high school teachers and students in Taiwan : a structural equation model analysis. Educational Technology Research and Development, 64(3), 533-554. https://doi.org/10.1007/s11423-016-9432-y

Matzavela V. \& Alepis E. (2021). M-learning in the covid-19 era: physical vs digital class. Education and Information Technologies (2021) 26:7183-7203. https://doi.org/10.1007/s10639-021-10572$\underline{6}$

Md Yusoff Daud, Fariza Khalid, \& Norhayati Yusoff. (2016). Tahap kesediaan pelajar prasiswazah UKM dalam penggunaan m-pembelajaran. International Conference on Education and Regional Development 2016 (ICERD 2016), (November), 478-488. Bandung.

Munirah, S., Mohd, F. J., Noor, S. M. S., \& Julia, M. Y. (2021). Tinjauan keberkesanan pembelajaran secara dalam talian ketika pandemik covid-19: perspektif pelajar sains kejuruteraan politeknik Ibrahim Sultan. Jurnal Dunia Pendidikan, 3(1), 374-384.

Mohamed Amin Embi, \& Norazah Mohd Nordin. (2013). Mobile learning: Malaysian initiatives \& research findings. In Universiti Kebangsaan Malaysia. Bangi: Universiti Kebangsaan Malaysia.

Mohd Razali Abd Samad, Zanaton Hj Ihsan \& Fariza Khalid. (2021). The use of mobile learning in teaching and learning session during the covid-19 pandemic in Malaysia. Journal of Contemporary Social Science and Educational Studies, 1(2), 57.

Mohd Reza Beik Zadeh. (2012). Edutainment and mLearning: Practical game. In Saedah Siraj, Fadzilah Siraj, \& Muhammad Helmi (Eds.), m-Learning: A New Dimension of Curriculum Advancement (pp. 103-115). Kuala Lumpur: University of Malaya Press.

Mohd Zulhasnan Mat, Fadli Bacho \& Sharifuddin Rapin. (2019). Kesediaan Pelajar dalam MPembelajaran bagi Pengajaran dan Pembelajaran di Kolej Komuniti Tawau, Sabah. Politeknik \& Kolej Komuniti Journal of Life Long Learning, 3(1), 103-111.

Moorthy, K., T, L. C., Wei, K. M., Tan, P., Mei, Z., Yee, C. Y., ... Xin, Y. M. (2019). Is facebook useful for learning? A study in private universities in Malaysia. Computers \& Education, 130, 94-104. https://doi.org/10.1016/j.compedu.2018.12.002

Naseer M. Sabah. (2016). Exploring students' awareness and perceptions: Influencing factors and individual differences driving m-learning adoption. Computers in Human Behavior, 65, 522-533. https://doi.org/10.1016/j.chb.2016.09.009

Nor Fadzleen Sa'don, Halina Mohamad Dahlan, \& Ibrahim, A. (2013). Usage of mobile learning in Malaysian secondary education: Stakeholders' view. Journal of Information Systems Research and Innovation, 6, 42-50. 
Ooi, K., Hew, J., \& Lee, V. (2018). Could the mobile and social perspectives of mobile social learning platforms motivate learners to learn continuously? Computers \& Education, 120, 127-145. https://doi.org/10.1016/j.compedu.2018.01.017

Pimmer, C., Brühlmann, F., Odetola, T. D., Oluwasola, D. O., Dipeolu, O., \& Ajuwon, A. J. (2019). Facilitating professional mobile learning communities with instant messaging. Computers and Education, 128, 102-112. https://doi.org/10.1016/j.compedu.2018.09.005

Saedah Siraj, \& Muhammad Helmi. (2012). Curriculum transformation within mLearning environments. In m-Learning: A New Dimension of Curriculum Advancement (pp. 17-38). Kuala Lumpur: University of Malaya Press.

Saikat S., Dhillon J.S, Wan Fatimah Wan Ahmad \& Robiatul A'dawiah Jamaluddin (2021). A

systematic review of the benefits and challenges of mobile learning during the covid-19 pandemic. Educ. Sci. 2021, 11, 459. https://doi.org/10.3390/educsci11090459

Tengku Sarina Aini Tengku Kasim, Nur Atikah Miasan \& Yusmini Md Yusoff (2020). Cabaran Pembelajaran Abad Ke-21 Dalam Kalangan Guru Novis Pendidikan Islam Di Malaysia. International Journal of Education, Psychology and Counselling, 5(37), 206-220.

Wahyudin Darmalaksana, R. Yuli Ahmad Hambali, Ali Masrur \& Muhlas. (2020). Analisis Pembelajaran Online Masa WFH Pandemic Covid-19 sebagai Tantangan Pemimpin Digital Abad 21. Karya Tulis Ilmiah (KTI) Masa Work From Home (WFH) Covid-19 UIN Sunan Gunung Djati Bandung Tahun 2020, 1-12.

Wan Mohd Fauzy. (2012). Roles of Instructor and Learner in mLearning. In Saedah Siraj, Fadzilah Siraj, \& Muhammad Helmi (Eds.), m-Learning: A New Dimension of Curriculum Advancement (pp. 49-57). Kuala Lumpur: University of Malaya Press. 